\title{
The economic activities of sub-Saharan immigrants: informal sector and low wages
}

\author{
Mourad Jabrane ${ }^{1 *}$, Mouhsine Idali ${ }^{2}$, and Redouane Madi ${ }^{1}$ \\ ${ }^{1}$ Department of geography, Sultan Moulay Slimane University, Beni Mellal, Morrocco \\ ${ }^{2}$ Teacher in the Faculty of arts and human sciences, Sultan Moulay Slimane University, Morrocco
}

\begin{abstract}
Immigration is a social phenomenon that leads to the immigrant's sociological and economic reorganization, the immigrant often finds himself obliged to overcome the challenges of the economic integration into the host society. So, this study is an analysis of the economic activities of 102 sub-Saharan immigrants who live and work in the urban space of Rabat, and one semi-structured questionnaire is used to explores the specificities of the sectors of their economic activities. The results obtained confirm the findings of various authors affirming the recourse of immigrants to informal economic activity sectors generating low wages.
\end{abstract}

\section{Introduction}

Immigration -as the displacement of an individual or groups of individuals from one environment (place of origin) to another one- undoubtedly leads to psychological, sociological and cultural reorganization affecting the entire life of the immigrant who finds himself confronted with events that do not always seem to be in his favour. The observation of the socioeconomic circumstances of sub-Saharan immigrants residing in Morocco shows the emergence of findings related to the fragility of the economic activities. A lot of theoretical and empirical studies have confirmed this situation.

In this sense, this study aims to analyse the factors influencing the occupation of lowincome economic activities by sub-Saharan immigrants.

Methodologically, this is an empirical study that uses semi-structured questionnaire and done at the level of the urban space of Rabat. However, the number of sub-Saharan immigrants residing and working in this space remains undetermined because there is an absence of precise statistical data concerning their number and socioeconomic characteristics, as well as the relative instability of the number of immigrants in the studied space.

To ensure coverage of the entire urban territory of Rabat by the study, and taking into account the lack of statistical data relating to the number of sub-Saharan immigrants practising economic activities for each urban district of Rabat, the sampling is oriented towards the adoption of a sample of $\mathrm{n}=102$ sub-Saharan immigrants, divided equally from $\mathrm{n}=17$ for each of the six urban districts of Rabat, using network sampling. This sampling

* Corresponding author: jbrnmourad@gmail.com 
will prevent a focusing on the economic activity characterizing one urban community or neglecting other one

\section{Economic activities of sub-Saharan immigrants: Sector analysis}

\subsection{Sectors of economic activity between the formal and the informal}

The income from economic activities is the cornerstone of activism for any individual in any society. They allow access to the demands of human life and the response to the necessary needs of individuals. However, the economic activities carried out by subSaharan immigrants in the city of Rabat are essentially, part of informal sector, known for its low income and multiple constraints.

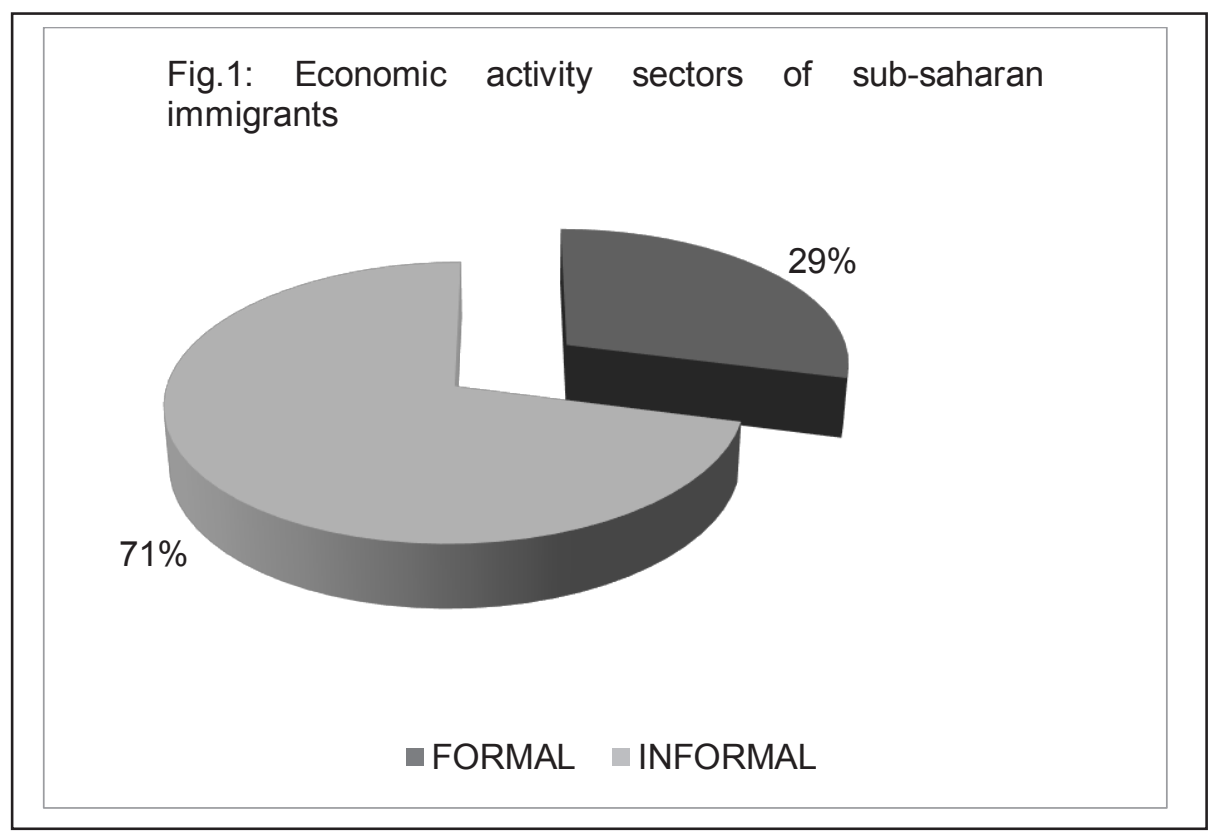

Fig.1. Economic activity sectors of sub-Saharan immigrants in the urban area of Rabat

The survey results show that only $29 \%$ of sub-Saharan immigrants work in the formal sector. These results have led us to further investigate the criteria used by sub-Saharan immigrants to describe one or another of the informal sectors. The results obtained in this context are presented as follows: 


\subsection{Informal criteria of the economic activity sector}

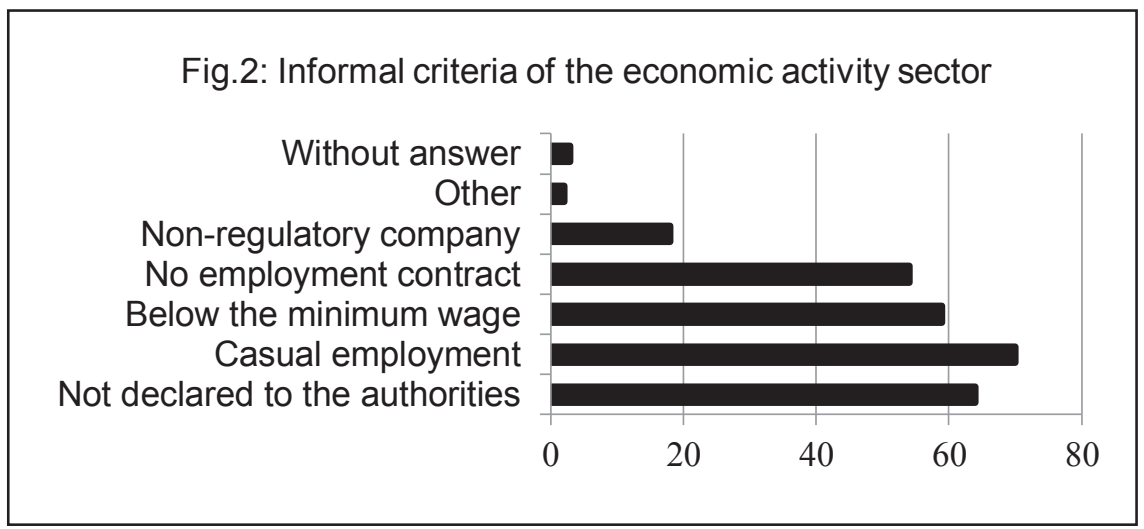

Fig.2. Informal criteria of the economic activity sector

In $70 \%$ of cases, casual or short-term employment is a common characteristic of the sectors of activity of immigrants, followed by undeclared work to the authorities (64\%), and 59\% of cases, respondents reported that the wages received are lower than the legal minimum wage and are considered to belong to the informal sector. The lack of an employment contract also remains a significant criterion $(54 \%)$ of the informal nature of the sector of activity.

These results are reminiscent of almost all of the informal criteria for sectors of activity adopted by the 17th International Conference of Labor Statisticians which shows a real tendency of sub-Saharan immigrants towards informal economic activities.

When it comes to the activity sectors most occupied by sub-Saharan immigrants, the results are as follows:

\subsection{Economic activity sectors}

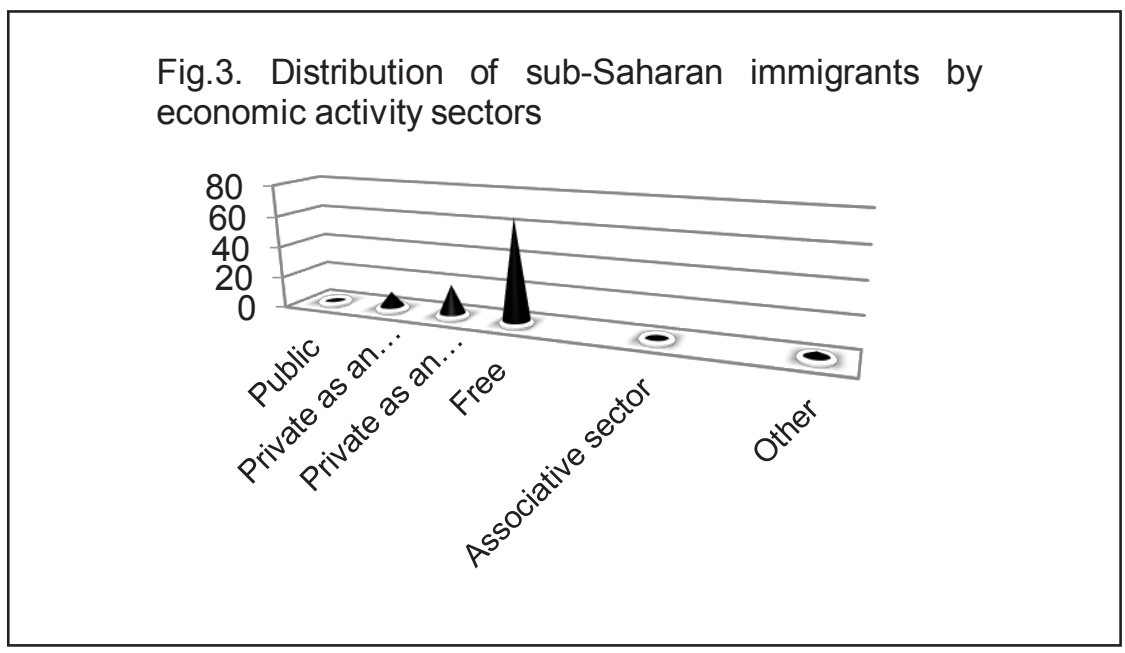

Fig. 3 Distribution of sub-Saharan immigrants by economic activity sectors 
Considering their legal status (50\% of respondents are administratively unregulated) and the urban context where economic activity takes place, it appears that sub-Saharan immigrants tend towards liberal economic activities (65\%) followed by private sector activities, as employees (22\%), that coincides with the data raised by Milton Santos (1968) who considered the liberal sector as "the primitive tertiary" or the sector of the urban population with service activities generally little paid and no constituting permanent employment. They are people ready to do almost anything, ready to sell their labour power by the day, by the week or by the month, and to accept a fixed remuneration for such or such task.

\section{Economic activities of sub-Saharan immigrants: the current activities}

\subsection{Economic activities carried out by sub-Saharan immigrants:}

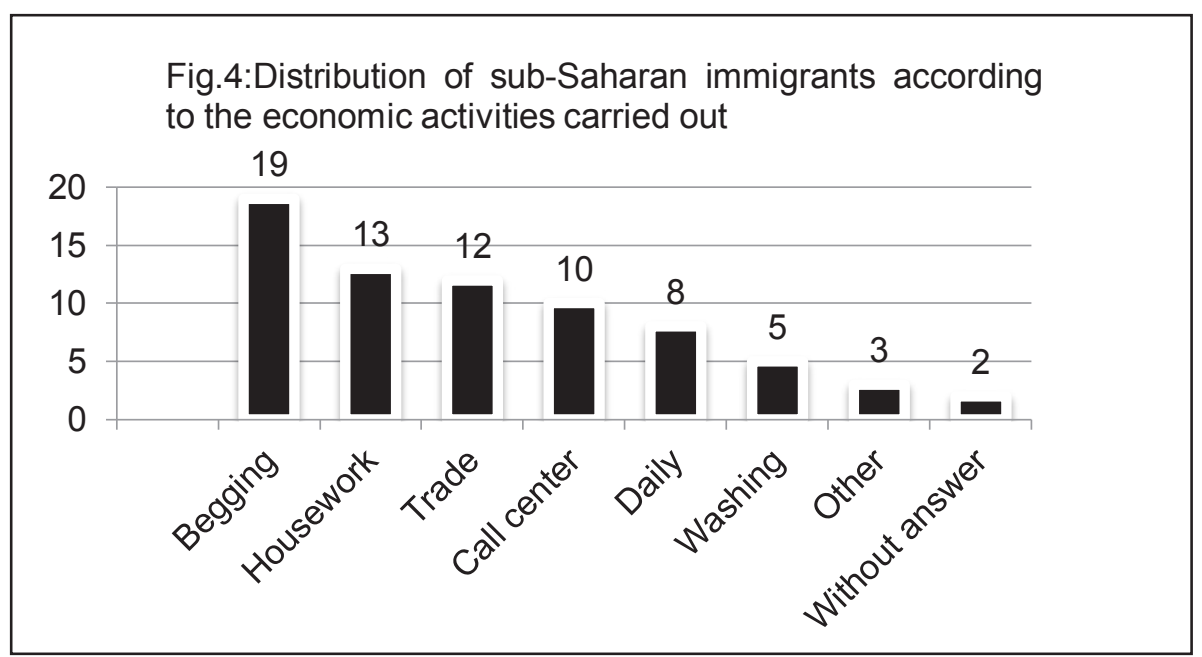

Fig. 4. Distribution of sub-Saharan immigrants according to the economic activities carried out

Immigrants living in urban areas are often considered marginal in the economy. They will especially amplify the tertiary sectors that Milton Santos (1968) called "URBAN PARASITISM". In this sense, graph 4 shows that small informal commerce remains the most represented economic activity in the circles of sub-Saharan immigrants in Rabat (29\%). The informal commerce indicates in particular, the " Ferracha " exercised on the edges of the streets and in ancient city markets.

These are economic activities carried out by immigrants in well-defined geographic areas to create their clientele and to work in a social context. Indeed, the entry into the labour market by this route is often pushed by compatriot immigrants already in place that facilitate newcomers to learn the acquisition and marketing of various goods and they facilitate their cohabitation with local authorities preventing the exercise of these activities.

Begging is also very present as an economic activity carried out in particular by newcomers to Rabat and people who are not administratively regularized. Begging is done by the subSaharans, especially at roundabouts and streets in the "Lkamra" and Hassan districts, it is done provisionally pending administrative regularization that will eventually allow access to another work opportunity. The other activities undertaken are: workers in car washes, traders in shops located in particular at "Kissariat Chabab" in Bab Lhad and Yakoub 
Lmansour, almost all of whom is specialized in the sale of African products (jewellery, handicraft products, leather products, ...), hairdressing salons whose owners and workers are sub-Saharan immigrants. These new economic activities confirm the observations of Simmel. He said that the seller must seek to provoke ever new and individualized needs in those who seek to seduce. The need to specialize production, to find a source of income that is not yet exhausted or a function that is not easily replaced, pushes for differentiation, refinement, enrichment of the public needs (Simmel, 1903).

As for the household, this activity is organized by the associations to benefit sub-Saharan women in a regular situation. Similarly, work in call centres is granted to legal immigrants under the supervision of associations of sub-Saharan immigrants, note the case of the "Webhelp" call centre employing Senegalese.

The results of analysis of economic activities carried out by sub-Saharan immigrants in the urban area of Rabat may lead us to organize them according to the wages obtained. The results in this context are as follows.

\subsection{Distribution of respondents according to the activity carried out and the salaries obtained}

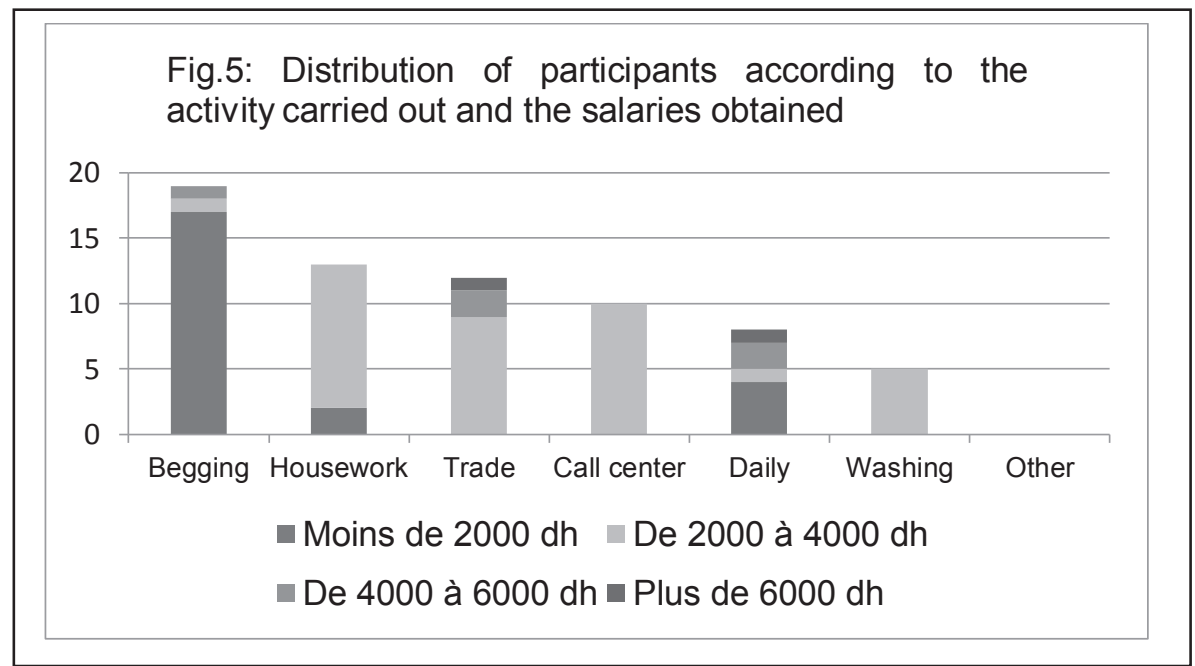

Fig.5. Distribution of participants according to the activity carried out and the salaries obtained

It appears that the highest wages are paid by traders and day labourers, while call centre workers, housekeepers and petty traders are paid amounts between 2000 and $4000 \mathrm{DH}$. The lowest-paid is immigrants resorting to begging.

However, three-quarters of the total respondents have an income between $2000 \mathrm{DH}$ and $4000 \mathrm{DH}$, and $14 \%$ have a salary below $2000 \mathrm{DH}$. The average income is $2416.83 \mathrm{DH}$ with a minimum of $800 \mathrm{DH}$ and a maximum of $6500 \mathrm{DH}$. The standard deviation or the mean of the squares of the deviations around the mean income is 967.79 .

These results illustrate a difference between the incomes of sub-Saharan workers and Moroccans. They record a low-income rate in urban areas of $(24.3 \%)$, on an employment rate of people aged 15 and over equal to $34.9 \%$ ( HCP, 2016). 
In short, the primitive tertiary sector, as Milton Santos said, remains the sector of activity that reigns in the circles of sub-Saharan immigrants in Rabat, the primitive tertiary sector interests people ready to exercise all the encountered economic activities; to sell their labour-power, without conditions, neither temporal nor spatial, and to accept any proposed remuneration.

However, there is no proved relationship between the increase in the flow of immigrants and the decrease in the wages of natives. The arrival of new immigrants only has an income reduction effect on immigrants who already exist in reception space.

This illustration is confirmed in the studies of Grossman (1982) concluded that an additional immigrant influx has only a very limited or negligible impact on the employment of nationals.

The number of immigrants leads to only a minimal fall (between $0.2 \%$ and $0.3 \%$ ) in the wages of nationals, a result also obtained by Borjas (1987) who concluded that the only significant effect of the level of immigration on wages is related to the wages of the immigrants themselves.

\section{Synthesis:}

The conclusions drawn by the analysis of the incomes of sub-Saharan immigrants in the urban area of Rabat are essentially the recording of generally low incomes. They are caracterised by the approximation to the average salary of Moroccans, in addition to the disparities between their salaries, that are relatively high, and very low minimum wage. This situation is related to the Moroccan working context marked by:

- Intense competition for access to work, more marked among sub-Saharan immigrants themselves;

- Recourse to available jobs which are generally casual or short-term jobs not declared to the authorities;

- The wages affected are lower than the legal minimum wage in Morocco;

- The preponderance of immigrants' work in the informal sector with a lack of a work contract and a virtual absence of the public sector;

So, sub-Saharan immigrants choose their job site corresponding to the most favourable criteria in terms of economic dynamics, social and geographic reasons that allows adaptation with all constraints encountered.

\section{References}

1. Haut Commissariat au Plan, employment and unemployment activities, first results, 99 (2016)

2. International Labor Office (ILO), Measuring Informality: A Statistical Manual on the Informal Sector and Informal Employment, Geneva (2013)

3. G. Simmel, Metropolises and mentality, 23 (1903)

4. S. Milton, Urban geography and the economy of cities in underdeveloped countries. In: Revue de géographie de Lyon, vol. 43, No. 4, 363 and 374 (1968)

5. J.B. GROSSMAN, The substituability of natives and immigrants in production. Review of economies and statistics, 64 (4), 596-603 (1982)

6. G.J. BORJAS, Immigrants, Minorities, and Labor Market Compétition. Industrial and Labor Relations Review, 40 (3), 382-392 (1987) 